BLS 32, No 1 2006. DOI: http://dx.doi.org/10.3765/bls.v32i1.3450 (published by the Berkeley Linguistics Society and the Linguistic Society of America)

\title{
When Gesture Is and Is Not Language ${ }^{1}$
}

\author{
SUSAN GOLDIN-MEADOW \\ University of Chicago
}

\section{Introduction}

Consider a profoundly deaf child growing up in the United States whose hearing parents have not exposed him to American Sign Language and whose hearing losses have prevented him from acquiring English. You might think that a child in this circumstance would be unable to communicate, but in fact the child communicates quite well. When shown a picture of a shovel stuck in sand, he uses his hands to comment not on the particular shovel in the picture, but on snow shovels in general: he gestures "dig", points at the picture of the shovel, gestures "pull-onboots", points outside, points downstairs, points at the shovel picture, gestures "dig", and gestures "pull-on-boots". The child has used gesture to convey several propositions about snow shovels - how they are used (to dig), when they are used (when boots are worn), where they are used (outside), and where they are kept (downstairs).

It is not at all unusual for people to use their hands when communicating; hearing speakers routinely gesture when they talk, no matter what language they speak (Feyereisen and de Lannoy 1991, Kendon 1980, McNeill 1992). What is striking about the deaf child's gestures, however, is that they are not structured like hearing speakers' gestures. When gesture is used on its own to communicate, it begins to take on linguistic properties - even when the gesturer is a child who has not been exposed to a conventional language. In contrast, when gesture is used along with speech, it still communicates, but does so in an unsegmented form not found in natural languages.

I begin this paper with a description of the gestures the deaf child produces without speech. These gestures assume the full burden of communication and take on a language-like form: they are language. This phenomenon stands in contrast to the gestures hearing speakers produce with speech, which I describe in the

\footnotetext{
${ }^{1}$ This research was supported by grants from the National Science Foundation (BNS 8810879), the National Institute of Deafness and Other Communication Disorders (R01 DC00491), the National Institutes of Child Health and Human Development (R01 HD47450 and P01 HD 40605), and the Spencer Foundation.
} 
second part of the paper. These gestures share the burden of communication with speech and do not take on a language-like form: they are part of language and, as such, often reflect speakers' unspoken thoughts (and may even play a role in creating those thoughts).

\section{Gesture without Speech Takes Over the Forms and Functions of Language}

\subsection{Background on Deafness and Language-Learning}

When deaf children are exposed to sign language from birth, they learn that language as naturally as hearing children learn spoken language (Newport and Meier 1985). However, $90 \%$ of deaf children are not born to deaf parents who could provide early access to sign language. Rather, they are born to hearing parents who, quite naturally, expose their children to speech. Unfortunately, it is extremely uncommon for deaf children with severe to profound hearing losses to acquire spoken language without intensive and specialized instruction. Even with instruction, their acquisition of speech is markedly delayed (Conrad 1979, Mayberry 1992).

The ten children my colleagues and I studied were severely to profoundly deaf (Goldin-Meadow 2003a). Their hearing parents had decided to educate them in oral schools where sign systems are neither taught nor encouraged. At the time of our observations, the children ranged in age from 1;2 to 4;10 (years;months) and had made little progress in oral language, occasionally producing single words but never combining those words into sentences. In addition, they had not been exposed to a conventional sign system of any sort (e.g. American Sign Language or a manual code of English). The children thus knew neither sign nor speech.

Under such inopportune circumstances, these deaf children might be expected to fail to communicate, or perhaps to communicate only in non-symbolic ways. The impetus for symbolic communication might require a language model, which all of these children lacked. However, this turns out not to be the case. Many studies have shown that deaf children will spontaneously use gestures, called "homesigns", to communicate if they are not exposed to a conventional sign language (Fant 1972, Lenneberg 1964, Moores 1974, Tervoort 1961). The child described at the beginning of this paper is an excellent example. Children who use gesture in this way are clearly communicating. But are they communicating in a language-like way? The focus of my work has been to address this question. I do so by identifying linguistic constructions that the deaf children use in their gesture systems. These properties of language, which the children are able to fashion without the benefit of linguistic input, are what I call the "resilient" properties of language (Goldin-Meadow 1982, 2003a).

\subsection{The Resilient Properties of Language}

Table 1 lists the resilient properties of language that we have found thus far in the ten deaf children's gesture systems (Goldin-Meadow 2003a). There may, of

course, be many others; just because we have not found a particular property in a 
deaf child's homesign gesture system does not mean it is not there. The table lists properties at the word and sentence levels, as well as properties of language use, and details how each property is instantiated in the deaf children's gesture systems.

Table 1. The resilient properties of language

\begin{tabular}{|c|c|}
\hline The Resilient Property & As Instantiated in the Deaf Children's Gestures \\
\hline \multicolumn{2}{|l|}{ Words } \\
\hline Stability & $\begin{array}{l}\text { Gesture forms are stable and do not change capriciously with } \\
\text { changing situations. }\end{array}$ \\
\hline Paradigms & $\begin{array}{l}\text { Gestures consist of smaller parts that can be recombined to } \\
\text { produce new gestures with different meanings. }\end{array}$ \\
\hline Categories & $\begin{array}{l}\text { The parts of gestures are composed of a limited set of forms, each } \\
\text { associated with a particular meaning. }\end{array}$ \\
\hline Arbitrariness & $\begin{array}{l}\text { Pairings between gesture forms and meanings can have arbitrary } \\
\text { aspects, albeit within an iconic framework. }\end{array}$ \\
\hline Grammatical Functions & $\begin{array}{l}\text { Gestures are differentiated by the noun, verb, and adjective } \\
\text { grammatical functions they serve. }\end{array}$ \\
\hline \multicolumn{2}{|l|}{ Sentences } \\
\hline Underlying Frames & Predicate frames underlie gesture sentences. \\
\hline Deletion & $\begin{array}{l}\text { Consistent production and deletion of gestures within a sentence } \\
\text { mark particular thematic roles. }\end{array}$ \\
\hline Word Order & $\begin{array}{l}\text { Consistent orderings of gestures within a sentence mark particular } \\
\text { thematic roles. }\end{array}$ \\
\hline Inflections & Consistent inflections on gestures mark particular thematic roles. \\
\hline Recursion & Complex gesture sentences are created by recursion. \\
\hline Redundancy Reduction & $\begin{array}{l}\text { Redundancy is systematically reduced in the surface of complex } \\
\text { gesture sentences. }\end{array}$ \\
\hline \multicolumn{2}{|l|}{ Language Use } \\
\hline Here-and-Now Talk & $\begin{array}{l}\text { Gesturing is used to make requests, comments, and queries about } \\
\text { the present. }\end{array}$ \\
\hline Displaced Talk & $\begin{array}{l}\text { Gesturing is used to communicate about the past, future, and } \\
\text { hypothetical. }\end{array}$ \\
\hline Narrative & Gesturing is used to tell stories about self and others. \\
\hline Self-Talk & Gesturing is used to communicate with oneself. \\
\hline Meta-Language & Gesturing is used to refer to one's own and others' gestures. \\
\hline
\end{tabular}

\subsubsection{Words}

The deaf children's gesture words have five properties that are found in all natural languages. The gestures are stable in form, although they need not be. It would be easy for the children to make up a new gesture to fit every new situation (and, indeed, that appears to be what hearing speakers do when they gesture along with their speech, cf. McNeill 1992). But that is not what the deaf children do. They develop a stable store of forms that they use in a range of situations: they develop a lexicon, an essential component of all languages (Goldin-Meadow, Butcher, 
Mylander, and Dodge 1994).

Moreover, the gestures the children develop are composed of parts that form paradigms, or systems of contrasts. When the children invent a gesture form, they do so with two goals in mind: the form must not only capture the meaning they intend (a gesture-world relation), but it must also contrast in a systematic way with other forms in their repertoire (a gesture-gesture relation). In addition, the parts that form these paradigms are categorical. For example, one child used a Fist handshape to represent grasping a balloon string, a drumstick, and handlebars-grasping actions requiring considerable variety in diameter in the real world. The child did not distinguish objects of varying diameters within the Fist category, but did use his handshapes to distinguish objects with small diameters as a set from objects with large diameters (e.g. a cup, a guitar neck, the length of a straw), which were represented by a CLarge hand. The manual modality can easily support a system of analog representation, with hands and motions reflecting precisely the positions and trajectories used to act on objects in the real world. But the children do not choose this route. They develop categories of meanings that, although essentially iconic, have hints of arbitrariness about them. The children do not, for example, all have the same form-meaning pairings for handshapes (Goldin-Meadow, Mylander, and Butcher 1995; Goldin-Meadow, Mylander, and Franklin 2006).

Finally, the gestures the children develop are differentiated by grammatical function. Some serve as nouns, some as verbs, some as adjectives. As in natural languages, when the same gesture is used for more than one grammatical function, that gesture is marked (morphologically and syntactically) according to the function it plays in the particular sentence (Goldin-Meadow et al. 1994). For example, if a child were to use a twisting gesture in a verb role, that gesture would likely be produced near the jar to be twisted open (i.e. it would be inflected); it would not be abbreviated; and it would be produced after a pointing gesture at the jar. In contrast, if the child were to use the twisting gesture in a noun role, the gesture would likely be produced in neutral position near the chest (i.e. it would not be inflected); it would be abbreviated (produced with one twist rather than several); and it would occur before the pointing gesture at the jar.

\subsubsection{Sentences}

The deaf children's gesture sentences have six properties found in all natural languages. Underlying each sentence is a predicate frame that determines how many arguments can appear along with the verb in the surface structure of that sentence (Goldin-Meadow 1985). For example, four slots underlie a gesture sentence about transferring an object, one for the verb and three for the arguments (actor, patient, recipient). In contrast, three slots underlie a gesture sentence about eating an object, one for the verb and two for the arguments (actor, patient).

Moreover, the arguments of each sentence are marked according to the thematic role they play. There are three types of markings that are resilient (GoldinMeadow and Mylander 1984, Goldin-Meadow et al. 1994): 


\section{When Gesture Is and Is Not Language}

(1) Deletion - The children consistently produce and delete gestures for arguments as a function of thematic role; for example, they are more likely to delete a gesture for the object or person playing the role of transitive actor (soldier in "soldier beats drum") than they are to delete a gesture for an object or person playing the role of intransitive actor (soldier in "soldier marches to wall") or patient (drum in "soldier beats drum").

(2) Word Order - The children consistently order gestures for arguments as a function of thematic role; for example, they place gestures for intransitive actors and patients in the first position of their two-gesture sentences (soldier-march, drum-beat).

(3) Inflection - The children mark gestures for arguments with inflections as a function of thematic role; for example, they displace a verb gesture in a sentence toward the object that is playing the patient role in that sentence (the "beat" gesture would be articulated near, but not on, a drum).

In addition, recursion, which gives natural languages their generative capacity, is a resilient property of language. The children form complex gesture sentences out of simple ones (Goldin-Meadow 1982). For example, one child pointed at me, produced a "wave" gesture, pointed again at me, and then produced a "close" gesture to comment on the fact that I had waved before closing the door-a complex sentence containing two propositions: "Susan waves" (proposition 1) and "Susan closes door" (proposition 2). The children systematically combine the predicate frames underlying each simple sentence following principles of sentential and phrasal conjunction. When there are semantic elements that appear in both propositions of a complex sentence, the children have a systematic way of reducing redundancy, as do all natural languages (Goldin-Meadow 1982, 1987).

\subsubsection{Language Use}

The deaf children use their gestures for five central functions that all natural languages serve. They use gesture to make requests, comments, and queries about things and events that are happening in the situation - that is, to communicate about the here-and-now. Importantly, however, they also use their gestures to communicate about the non-present: displaced objects and events that take place in the past, the future, or in a hypothetical world (Butcher, Mylander, and GoldinMeadow 1991; Morford and Goldin-Meadow 1997).

In addition to these rather obvious functions that language serves, the children use their gestures to communicate with themselves - to self-talk (Goldin-Meadow 2003a). They also use their gestures to refer to their own or to others' gesturesfor metalinguistic purposes (Singleton, Morford, and Goldin-Meadow 1993). And finally, the children use their gestures to tell stories about themselves and others- to narrate (Phillips, Goldin-Meadow, and Miller 2001). They tell stories about events they or others have experienced in the past, events they hope will 
occur in the future, and events that are flights of imagination. For example, in response to a picture of a car, one child produced a "break" gesture, an "away" gesture, a pointing gesture at his father, a "car-goes-onto-truck" gesture. He paused and produced a "crash" gesture and repeated the "away" gesture. The child was telling us that his father's car had crashed, broken, and gone onto a tow truck. Note that, in addition to producing gestures to describe the event itself, the child produced what we have called a narrative marker, the "away" gesture, which marks a piece of gestural discourse as a narrative in the same way that "once upon a time" is often used to signal a story in spoken discourse.

\subsection{Using the Spontaneous Gestures of Speakers as Input}

The deaf children we study are not exposed to a conventional sign language and thus cannot be fashioning their gestures after such a system. They are, however, exposed to the gestures that their hearing parents use when they speak. These gestures are likely to serve as relevant input to the gesture systems that the deaf children construct. The question is what does this input look like and how do the children use it?

We first ask whether the gestures that the hearing parents use with their deaf children exhibit the same structure as their children's gestures. If so, these gestures could serve as a model for the deaf children's system. If not, we have an opportunity to observe how the children transform the input they do receive into a system of communication that has many of the properties of language.

\subsubsection{The Hearing Parents' Gestures Are Not Structured Like Their Deaf Children's}

Hearing parents gesture when they talk to young children (Bekken 1989; Shatz 1982; Iverson, Capirci, Longobardi, and Caselli 1999), and the hearing parents of our deaf children are no exception. The deaf children's parents were committed to teaching them to talk and therefore talked to their children as often as they could. And when they talked, they gestured.

We looked at the gestures that the hearing mothers produced when talking to their deaf children. However, we looked at them not as they were meant to be looked at, but as a deaf child might look at them. We turned off the sound and analyzed the gestures using the same analytic tools that we used to describe the deaf children's gestures (Goldin-Meadow and Mylander 1983, 1984). We found that the hearing mothers' gestures do not have structure when looked at from a deaf child's point of view.

Going down the list of resilient properties displayed in Table 1, we find no evidence of structure at any point in the mothers' gestures. With respect to gestural "words", the mothers did not have a stable lexicon of gestures (GoldinMeadow et al. 1994), nor were their gestures composed of categorical parts that either formed paradigms (Goldin-Meadow et al. 1995) or varied with grammatical function (Goldin-Meadow et al. 1994). With respect to gestural "sentences", the mothers rarely concatenated their gestures into strings and thus provided little 
data from which we (or their deaf children, for that matter) could abstract predicate frames or deletion, word order, and inflectional marking patterns (GoldinMeadow and Mylander 1984). Whereas all of the children produce complex sentences displaying recursion, only some of the mothers did, and they first produced these sentence types after their children (Goldin-Meadow 1982). With respect to gestural use, the mothers did not make displaced reference with their gestures (Butcher et al. 1991), nor did we find evidence of any of the other uses to which the children put their gestures, including story-telling (e.g. Phillips et al. 2001).

Of course, it may be necessary for the deaf children to see hearing people gesturing in communicative situations in order to get the idea that gesture can be appropriated for the purposes of communication. However, in terms of how the children structure their gestured communications, there is no evidence that this structure comes from the children's hearing mothers. Thus, although the deaf children may be using hearing people's gestures as a starting point, they go well beyond that point, transforming the gestures they see into a system that looks very much like language.

\subsubsection{How to Study the Deaf Child's Transformation of Gesture into Home- sign: A Cross-Cultural Approach}

How can we learn more about this process of transformation? The fact that hearing speakers across the globe gesture differently when they speak affords us an excellent opportunity to explore if, and how, deaf children make use of the gestural input that their hearing parents provide. For example, the gestures that accompany Spanish and Turkish look very different from those that accompany English and Mandarin. As described by Talmy (1985), Spanish and Turkish are verb-framed languages, whereas English and Mandarin are satellite-framed languages. This distinction depends primarily on the way in which the path of a motion is packaged. In a satellite-framed language, path is encoded outside of the verb (e.g. down in the sentence He flew down), and manner is encoded in the verb itself (flew). In contrast, in a verb-framed language, path is bundled into the verb (e.g. sale in the Spanish sentence Sale volando 'exits flying'), and manner is outside of the verb (volando). One effect of this typological difference is that manner is often omitted from Spanish sentences (Slobin 1996).

However, McNeill (1998) has observed an interesting compensation: although manner is omitted from Spanish speakers' talk, it frequently crops up in their gestures. Moreover, and likely because Spanish speakers' manner gestures do not co-occur with a particular manner word, their gestures tend to spread through multiple clauses (McNeill 1998). As a result, Spanish speakers' manner gestures are longer and may be more salient to a deaf child than the manner gestures of English or Mandarin speakers. Turkish speakers also produce gestures for manner relatively frequently. In fact, Turkish speakers commonly produce gestures that convey only manner (e.g. fingers wiggling in place $=$ manner alone vs. fingers wiggling as the hand moves forward = manner + path; cf. Ozyurek and Kita 1999, 
Kita 2000). Manner-only gestures are rare in English and Mandarin speakers.

These four cultures - Spanish, Turkish, American, and Chinese - thus offer an excellent opportunity to examine the effects of hearing speakers' gestures on the gesture systems developed by deaf children. Our plan in future work is to take advantage of this opportunity. If deaf children in all four cultures develop gesture systems with the same structure despite wide differences in the gestures they see, we will have strong evidence of the biases children themselves must bring to a communication situation. If, however, the children differ in the gesture systems they construct, we will be able to explore how a child's construction of a language-like gesture system can be influenced by the gestures he or she sees. We have already found that American deaf children exposed only to the gestures of their hearing English-speaking parents create gesture systems that are very similar in structure to the gesture systems constructed by Chinese deaf children exposed to the gestures of their hearing Mandarin-speaking parents (Goldin-Meadow and Mylander 1998). The question now is whether these children's gesture systems are different from those of Spanish and Turkish deaf children of hearing parents.

\subsection{An Experimental Manipulation of Gesture with and without Speech}

The hearing mothers of each of the deaf children in our studies were committed to teaching their children to speak. As a result, they never gestured without talking. And, like all speakers' gestures, the gestures that the hearing mothers produced formed an integrated system with the speech they accompanied (McNeill 1992). The mothers' gestures were thus constrained by speech and were not "free" to take on the resilient properties of language found in their children's gestures. The obvious question is what would happen if we forced the mothers to keep their mouths shut.

We did just that, although the participants in our study were undergraduates at the University of Chicago, not the deaf children's hearing mothers (GoldinMeadow, McNeill, and Singleton 1996). We asked English speakers who had no previous experience with sign language to describe a series of videotaped scenes using their hands and not their mouths. We then compared the resulting gestures to the gestures these same adults produced when asked to describe the scenes using speech.

We found that when using gesture on its own, the adults frequently combined their gestures into strings, and those strings were reliably ordered, with gestures for certain semantic elements occurring in particular positions in the string; that is, there was structure across the gestures at the sentence level. In addition, the verblike action gestures that the adults produced when using gesture on its own could be divided into handshape and motion parts, with the handshape of the action frequently conveying information about the objects in its semantic frame; that is, there was structure within the gesture at the word level. Neither of these properties appeared in the gestures that these same adults produced along with speech. Thus, only when asked to use gesture on its own did the adults produce gestures characterized by segmentation and combination. Moreover, they constructed these 


\section{When Gesture Is and Is Not Language}

gesture combinations with essentially no time for reflection on what might be fundamental to language-like communication.

The adults might have gotten the inspiration to order their gestures from their own English language. However, the particular order that they used in their gestures did not follow canonical English word order. For example, adults were asked to describe a doughnut-shaped object that arcs out of an ashtray. When using gesture without speech, the adults produced a gesture for the ashtray first, followed by a gesture for the doughnut, and finally a gesture for the arcing-out action (Goldin-Meadow et al. 1996, Gershkoff-Stowe and Goldin-Meadow 2002). Note that a typical description of this scene in English would follow a different order: The doughnut arcs out of the ashtray. The adults not only displayed a nonEnglish ordering pattern, but they also displayed a non-English deletion pattern when using gesture on it own. Moreover, the deletion pattern resembled the pattern found in the deaf children's gestures (Goldin-Meadow, Yalabik, and Gershkoff-Stowe 2000).

Although the adults incorporated many linguistic properties into the gestures they produced when using gesture on its own, they did not develop all of the properties found in natural language or even all of the properties found in the gesture systems of the deaf children. In particular, they failed to develop a system of internal contrasts in their gestures. When incorporating handshape information into their action gestures, they rarely used the same handshape to represent an object, unlike the deaf child whose handshapes for the same objects were consistent in form and in meaning (Singleton, Morford, and Goldin-Meadow 1993). Thus, a system of contrasts in which the form of a symbol is constrained by its relationship to other symbols in the system (as well as by its relationship to its intended referent) is not an immediate consequence of symbolically communicating information to another. The continued experience that the deaf children had with a stable set of gestures (cf. Goldin-Meadow et al. 1994) may be required for a system of contrasts to emerge in those gestures.

In sum, when gesture is called upon to fulfill the communicative functions of speech, it immediately takes on the properties of segmentation and combination that are characteristic of speech. The appearance of these properties in the adults' gestures is particularly striking given that these properties were not found in the gestures that these same adults produced when asked to describe the scenes in speech. When the adults produced gestures along with speech, they rarely combined those gestures into strings and rarely used the shape of the hand to convey any object information at all (Goldin-Meadow et al. 1996). In other words, they did not use their gestures as building blocks for larger units, either sentence or word units. Rather, they used their gestures to holistically and mimetically depict the scenes in the videotapes, as speakers typically do when they spontaneously gesture along with their talk, a topic to which we now turn. 
Susan Goldin-Meadow

\section{Gesture with Speech Reflects Thoughts that Do Not Fit into Speech 2.1. The Relation Between Gesture and Speech Predicts Readiness to Learn}

Gesture and speech encode meaning differently (Goldin-Meadow 2003b, Kendon 1980, McNeill 1992). Gesture conveys meaning globally, relying on visual and mimetic imagery. Speech conveys meaning discretely, relying on codified words and grammatical devices. Because gesture and speech employ such different forms of representation, it is difficult for the two modalities to contribute identical information to a message.

Nonetheless, the information conveyed in gesture and in speech can overlap a great deal. For example, consider a child asked first whether the amount of water in two identical glasses is the same, and then whether the amount of water in one of the glasses changes after it is poured into a low wide dish. The child says that the amounts of water in the two glasses are the same at the beginning, but different after the pouring transformation. When asked to explain this answer, the child focuses on the height of the water in the containers in both speech and gesture; he says It's different because this one's low and that one's tall while gesturing the height of the water first on the dish and then on the glass. The child is thus conveying a justification in gesture that overlaps a great deal with the justification in speech - a gesture-speech match (Church and Goldin-Meadow 1986).

However, there are instances when gesture conveys information that overlaps very little with the information conveyed in the accompanying speech. Consider, for example, a child who gives the same explanation as the first child in speech, but conveys different information in gesture. She produces a wide " $\mathrm{C}$ " hand representing the width of the water in the dish, followed by a narrow "C" hand representing the width of the water in the glass. This child is focusing on the height of the water in speech, but on its width in gesture. She has produced a gesture-speech mismatch (Church and Goldin-Meadow 1986).

Children who produce mismatches in their explanations of a task have information relevant to solving the task at their fingertips and could, as a result, be on the cusp of learning the task. If so, they ought to be particularly receptive to instruction on the task, and indeed they are. Children who produce gesture-speech mismatches prior to instruction on conservation problems of this sort are more likely to profit from that instruction than children who produce matches (Church and Goldin-Meadow 1986). This phenomenon is robust, found in learners of all ages on a wide variety of tasks taught by an experimenter: 5- to 9-year-olds learning a balance task (Pine, Lufkin, and Messer 2004); 9- to 10-year-olds learning a math task (Perry, Church, and Goldin-Meadow 1988; Alibali and Goldin-Meadow 1993); and adults learning a gears task (Perry and Elder 1996). The phenomenon is also found in naturalistic learning situations: toddlers learning their first word combinations (Goldin-Meadow and Butcher 2003, Iverson and Goldin-Meadow 2005, Ozcaliskan and Goldin-Meadow 2005); and school-aged children learning a mathematical concept from a teacher (Goldin-Meadow and Singer 2003). 


\subsubsection{Why Do Gesture-Speech Mismatches Predict Openness to Instruction?}

A speaker who produces a mismatch is expressing two ideas, one in speech and another in gesture. The fact that the speaker is entertaining two ideas on a single problem may lead to cognitive instability, which in turn can lead to change. If so, a task known to encourage the activation of two ideas ought to evoke mismatches. Tower of Hanoi is a well-studied puzzle that is most efficiently solved by activating subroutines at theoretically defined choice points. There is a great deal of evidence that adults and children do indeed activate two ideas (the subroutine and an alternative path) at particular choice points on the Tower of Hanoi problem (Anzai and Simon 1979, Bidell and Fischer 1994, Klahr and Robinson 1981). We might therefore expect mismatches to occur at just these moments, and they do. When asked to explain how they solved the Tower of Hanoi puzzle, both adults and children produce significantly more gesture-speech mismatchesexplanations in which speech conveys one path and gesture another-at the theoretically defined choice points than at non-choice points (Garber and GoldinMeadow 2002). Mismatches thus tend to occur at points known to activate two strategies.

We can also test this idea from the opposite direction: we can select a situation known to elicit gesture-speech mismatches and explore whether two ideas are activated simultaneously in this situation. Consider a group of children selected because they produced either gesture-speech mismatches or matches when explaining a math problem. These children were then asked to remember a list of words while at the same time solving the math problem. All of the children solved the problem incorrectly, but children known to be mismatchers worked harder to arrive at their incorrect answers than children known to be matchers: they remembered fewer words when solving the problems, suggesting that they were indeed activating more than one strategy (Goldin-Meadow, Nusbaum, Garber, and Church 1993). Producing mismatches appears to reflect the activation of two ideas at the same time (see also Thurnham and Pine 2006).

\subsubsection{Is the Information Found in Gesture in a Mismatch Unique to Gesture?}

When speakers produce a mismatch, the information conveyed in gesture in that mismatch is, by definition, not found in the accompanying speech. For example, the child in the conservation task described earlier conveyed width information in gesture but not in her accompanying speech. However, it is possible that, on the very next problem, this child might describe the widths of the containers in speech. Alternatively, the information found in the gesture component of a mismatch might be accessible only to gesture; if so, the child would not be able to talk about the widths of the containers on any of the problems.

The second alternative turns out to be the case, at least for children in the process of learning mathematical equivalence with respect to addition: children who convey a particular strategy in the gesture half of a mismatch on a math 
problem do not convey that strategy in speech on any of the math problems in the set (Goldin-Meadow, Alibali, and Church 1993). What this means is that children who produce mismatches have information in their repertoires that they know implicitly but cannot articulate. It also means that, as listeners, if we want to know that a child has this information in her repertoire, we need to watch the child as well as listen to her.

Thus, the gestures people produce as they explain a task reflect what they know about the task. But gesture may do more than reflect knowledge; it may play a role in changing that knowledge. Gesture has the potential to change knowledge in two non-mutually exclusive ways, explored in the next two sections.

\subsection{Gesture as a Mechanism of Change through Its Communicative Effects}

Gesture has the potential to function as a mechanism of change through its communicative effects. If gestures reflect the state of the speaker's knowledge, they could serve as a signal to others that the speaker is at a transitional point. If listeners are then sensitive to this signal, they may, as a consequence, change the way they interact with the speaker. In this way, speakers can play a role in shaping their learning environments just by moving their hands. The hypothesis here is simple: (i) speakers reveal information about their cognitive status through their gestures; (ii) people pay attention to those gestures and alter their input to the speaker accordingly; and (iii) speakers profit from this altered input. We have just reviewed evidence for point (i). The next question is whether people pay attention to the gestures speakers produce and modify their instruction in response. We explore this question in a one-on-one tutorial involving a teacher and an individual child.

\subsubsection{Do Teachers Alter Their Instruction in Response to Their Students' Gestures?}

In order for gesture to play an important role in learning, listeners must not only pay attention to gesture, but must be able to do so in naturalistic teaching situations. We therefore observed teachers spontaneously interacting with their students. Teachers were asked to observe children explaining how they solved a series of math problems to an experimenter. The teachers then gave the children individual instruction in mathematical equivalence. Each of the teachers, at times, picked up on information that their students produced uniquely in gesture, often translating that information into their own words (Goldin-Meadow, Singer, and Kim 1999).

Teachers do pay attention to their students' gestures. But do they alter their instruction in response to those gestures? Interestingly, the teachers did give different types of instruction to children who produced mismatches than to children who produced only matches. They used more different types of spoken strategies and more of their own gesture-speech mismatches when teaching children who produced mismatches (Goldin-Meadow and Singer 2003), and the 


\section{When Gesture Is and Is Not Language}

children who produced mismatches learned. But why? The children may have learned because their teachers gave them just the right instruction. Alternatively, they may have learned because they were ready to learn.

\subsubsection{Are the Adjustments Teachers Make in Response to Children's Gestures Good for Learning?}

We know that including gesture in instruction is, in general, good for learning (Church, Ayman-Nolley, and Mahootian 2004; Perry, Berch, and Singleton 1995; Valenzeno, Alibali, and Klatzky 2003). But to find out whether the particular adjustments that the teachers made in their math tutorials actually promote learning, we need to experimentally manipulate the numbers and types of strategies children are taught in speech and in gesture. Following a script, an experimenter taught children one or two strategies in speech and, at the same time, varied the relation between her speech and gestures: some children received no gesture at all, some received gestures that conveyed the same strategy as speech (matching gesture), and some received gestures that conveyed different strategies from speech (mismatching gesture). Children who were taught one spoken strategy were far more successful after instruction than children taught two; the teachers' spontaneous adjustments in the tutorials were wrong on this count. But the teachers were right about mismatches: children who were taught with mismatching gestures were far more successful after instruction than children taught with matching gestures or no gestures (Singer and Goldin-Meadow 2005). Getting two strategies in instruction was effective, but only when those two strategies were produced across modalities, one in speech and the other in gesture.

A conversation thus appears to take place in gesture alongside the conversation taking place in speech. Speakers use their hands to reveal their cognitive state to their listeners, who in turn use their hands to provide instruction that promotes learning.

\subsection{Gesture as a Mechanism of Change through Its Cognitive Effects}

Gesture has the potential to function as a mechanism of change through its cognitive effects. When faced with a difficult problem to solve, we often find it helpful to use a cognitive prop. For example, writing a problem down can reduce cognitive effort, thereby freeing up resources that can then be used to solve the problem. In other words, externalizing our thoughts can save cognitive effort that can then be put to more effective use. Gesture can externalize ideas and thus has the potential to affect learning by influencing learners directly.

Indeed, including gesture in instruction might be effective because it encourages learners to produce gestures of their own. Adults mimic nonverbal behaviors that their conversational partners produce (Chartrand and Bargh 1999), and even very young infants imitate nonverbal behaviors modeled by an experimenter (Meltzoff and Moore 1977). It would therefore not be at all surprising if schoolaged children were to imitate the gestures that their teachers produce, and indeed they do. More relevant to the point here is the fact that children who produce 
these gestures are more likely to succeed after instruction than children who do not (Cook and Goldin-Meadow 2006). Gesturing during instruction encourages children to produce gestures of their own, which in turn leads to learning. Children may be able to use their hands to change their minds.

But why? One reason may be because gesturing lightens our cognitive load. Adults and children were asked to explain how they solved a math problem while at the same time remembering a list of words or letters. Both groups were found to remember more items when they gestured during their math explanations than when they did not gesture (Goldin-Meadow, Nusbaum, Kelly, and Wagner 2001). Gesturing appears to save speakers cognitive resources on the explanation task, permitting the speakers to allocate more resources elsewhere-in this case, to the memory task.

But gesture might not be lightening the speaker's load. It might merely be shifting the load away from a verbal store, perhaps to a visuo-spatial store. The idea here is that gesturing allows speakers to convey in gesture information that might otherwise have gone into a verbal store. Lightening the burden on the verbal store should make it easier to do a simultaneously performed verbal task. If, however, the burden has really been shifted to a visuo-spatial store, it should be harder to perform a spatial task (recalling the location of dots on a grid) when simultaneously gesturing than when not gesturing. But gesturing continues to lighten the speaker's load even if the second task is a spatial one (Wagner, Nusbaum, and Goldin-Meadow 2004).

Perhaps gesturing lightens a speaker's load because it is a motor activity that energizes the system (Butterworth and Hadar 1989). If so, the type of gesture produced should not matter; it should only matter that a speaker gestures, not what the speaker gestures. But the number of items that speakers remember does depend on the meaning conveyed by gesture: speakers remember more items when their gestures convey the same information as their speech (one message) than when their gestures convey different information (two messages). Gesture's content thus determines demands on working memory, suggesting that gesture confers its benefits, at least in part, through its representational properties.

\section{Conclusion}

Gesture is chameleon-like in its form, and that form is tied to the function the gesture is serving. When gesture assumes the full burden of communication, acting on its own without speech, it takes on a language-like form, even when the gesturer is a young child who has not had access to a usable model of a conventional language. As such, gesture can reveal the linguistic biases that children bring to the task of communication. Interestingly, however, when gesture shares the burden of communication with speech, it loses its language-like structure, assuming instead a holistic and unsegmented form. Although not language-like in structure when it accompanies speech, gesture still forms an important part of language. It conveys information imagistically and, as such, has access to different information than does the verbal system. Gesture thus allows speakers to 
convey thoughts that may not easily fit into the categorical system that their conventional language offers (Goldin-Meadow and McNeill 1999). Moreover, gesture has the potential to go beyond reflecting thought to play a role in shaping it. Gesture can be part of language or can itself be language and thus sheds light on what it means to be a language.

\section{References}

Alibali, Martha Wagner, and Susan Goldin-Meadow. 1993. Gesture-Speech Mismatch and Mechanisms of Learning: What the Hands Reveal about a Child's State of Mind. Cognitive Psychology 25:468-523.

Anzai, Y., and Herbert A. Simon. 1979. The Theory of Learning by Doing. Psychological Review 86(3):124-140.

Bekken, Kaaren. 1989. Is There "Motherese" in Gesture? Ph.D. diss., University of Chicago.

Bidell, Thomas R., and Kurt W. Fischer. 1995. Developmental Transitions in Children's Early On-Line Planning. In M. M. Haith, J. B. Benson, R. J. Roberts, Jr., and B. F. Pennington, eds., The Development of Future-Oriented Processes. Chicago: University of Chicago Press.

Butcher, Cynthia, Carolyn Mylander, and Susan Goldin-Meadow. 1991. Displaced Communication in a Self-Styled Gesture System: Pointing at the NonPresent. Cognitive Development 6:315-342.

Butterworth, Brian, and Uri Hadar. 1989. Gesture, Speech, and Computational Stages: A Reply to McNeill. Psychological Review 96:168-174.

Chartrand, Tanya L., and John A. Bargh. 1999. The Chameleon Effect: The Perception-Behavior Link and Social Interaction. Journal of Personality and Social Psychology 76:893-910.

Church, Ruth Breckinridge, Saba Ayman-Nolley, and Shahrzard Mahootian. 2004. The Role of Gesture in Bilingual Education: Does Gesture Enhance Learning? International Journal of Bilingual Education and Bilingualism 7:303-319.

Church, Ruth Breckinridge, and Susan Goldin-Meadow. 1986. The Mismatch Between Gesture and Speech as an Index of Transitional Knowledge. Cognition 23:43-71.

Conrad, R. 1979. The Deaf Child. London: Harper and Row.

Cook, Susan Wagner, and Susan Goldin-Meadow. 2006. The Role of Gesture in Learning: Do Children Use Their Hands to Change Their Minds? Journal of Cognition and Development 7:211-232.

Fant, Louis J. 1972. Ameslan: An Introduction to American Sign Language. Silver Springs, MD: National Association of the Deaf.

Feyereisen, Pierre, and J.-D. de Lannoy. 1991. Gestures and Speech: Psychological Investigations. Cambridge University Press.

Garber, Phillip, and Susan Goldin-Meadow. 2002. Gesture Offers Insight into 
Problem-Solving in Children and Adults. Cognitive Science 26:817-831.

Gershkoff-Stowe, Lisa, and Susan Goldin-Meadow. 2002. Is There a Natural Order for Expressing Semantic Relations? Cognitive Psychology 45(3):375-412.

Goldin-Meadow, Susan. 1982. The Resilience of Recursion: A Study of a Communication System Developed Without a Conventional Language Model. In Eric Wanner and Lila R. Gleitman, eds., Language Acquisition: The State of the Art. New York: Cambridge University Press.

Goldin-Meadow, Susan. 1985. Language Development under Atypical Learning Conditions: Replication and Implications of a Study of Deaf Children of Hearing Parents. In K. Nelson, ed., Children's Language, Vol. 5, 197-245. Hillsdale, NJ: Erlbaum.

Goldin-Meadow, Susan. 1987. Underlying Redundancy and Its Reduction in a Language Developed Without a Language Model: The Importance of Conventional Linguistic Input. In Barbara Lust, ed., Studies in the Acquisition of Anaphora: Applying the Constraints, Vol. II, 105-133. Boston, MA: D. Reidel Publishing Company.

Goldin-Meadow, Susan. 2003a. The Resilience of Language: What Gesture Creation in Deaf Children Can Tell Us about Language-Learning in General. New York: Psychology Press.

Goldin-Meadow, Susan. 2003b. Hearing Gesture: How Our Hands Help Us Think. Cambridge, MA: Harvard University Press.

Goldin-Meadow, Susan, Martha W. Alibali, and Ruth Breckinridge Church. 1993. Transitions in Concept Acquisition: Using the Hand to Read the Mind. Psychological Review 100:279-297.

Goldin-Meadow, Susan, and Cynthia Butcher. 2003. Pointing Toward Two-Word Speech in Young Children. In Sotaro Kita, ed., Pointing: Where Language, Culture, and Cognition Meet. NJ: Erlbaum.

Goldin-Meadow, Susan, Cynthia Butcher, Carolyn Mylander, and Mark Dodge. 1994. Nouns and Verbs in a Self-Styled Gesture System: What's in a Name? Cognitive Psychology 27:259-319.

Goldin-Meadow, Susan, San Kim, and Melissa Singer. 1999. What the Teacher's Hands Tell the Student's Mind about Math. Journal of Educational Psychology 91:720-730.

Goldin-Meadow, Susan, and David McNeill. 1999. The Role of Gesture and Mimetic Representation in Making Language the Province of Speech. In Michael C. Corballis and Stephen Lea, eds., The Descent of Mind, 155-172. Oxford: Oxford University Press.

Goldin-Meadow, Susan, David McNeill, and Jenny Singleton. 1996. Silence Is Liberating: Removing the Handcuffs on Grammatical Expression in the Manual Modality. Psychological Review 103:34-55.

Goldin-Meadow, Susan, and Carolyn Mylander. 1983. Gestural Communication in Deaf Children: The Non-Effects of Parental Input on Language Development. Science 221:372-374. 


\section{When Gesture Is and Is Not Language}

Goldin-Meadow, Susan, and Carolyn Mylander. 1984. Gestural Communication in Deaf Children: The Effects and Non-Effects of Parental Input on Early Language Development. Monographs of the Society for Research in Child Development 49:1-121.

Goldin-Meadow, Susan, and Carolyn Mylander. 1998. Spontaneous Sign Systems Created by Deaf Children in Two Cultures. Nature 91:279-281.

Goldin-Meadow, Susan, Carolyn Mylander, and Cynthia Butcher. 1995. The Resilience of Combinatorial Structure at the Word Level: Morphology in SelfStyled Gesture Systems. Cognition 56:195-262.

Goldin-Meadow, Susan, Carolyn Mylander, and Amy Franklin. 2006. How Children Make Language out of Gesture: Morphological Structure in Gesture Systems Developed by American and Chinese Deaf Children. Cognitive Psychology [in press].

Goldin-Meadow, Susan, Howard Nusbaum, Phillip Garber, and Ruth Breckinridge Church. 1993. Transitions in Learning: Evidence for Simultaneously Activated Strategies. Journal of Experimental Psychology: Human Perception and Performance 19:92-107.

Goldin-Meadow, Susan, Howard Nusbaum, Spencer D. Kelly, and Susan Wagner. 2001. Explaining Math: Gesturing Lightens the Load. Psychological Science 12:516-522.

Goldin-Meadow, Susan, and Melissa A. Singer. 2003. From Children's Hands to Adults' Ears: Gesture's Role in Teaching and Learning. Developmental Psychology 39:509-520.

Goldin-Meadow, Susan, Elif Yalabik, and Lisa Gershkoff-Stowe. 2000. The Resilience of Ergative Structure in Language Created by Children and by Adults. Proceedings of Boston University Conference on Language Development 24:343-353.

Iverson, Jana M., and Susan Goldin-Meadow. 2005. Gesture Paves the Way for Language Development. Psychological Science 16:368-371.

Iverson, Jana M., O. Capirci, E. Longobardi, and M. C. Caselli. 1999. Gesturing in Mother-Child Interaction. Cognitive Development 14:57-75.

Kendon, Adam. 1980. Gesticulation and Speech: Two Aspects of the Process of Utterance. In M. R. Key, ed., Relationship of Verbal and Nonverbal Communication, 207-228. The Hague: Mouton.

Kita, Sotaro. 2000. How Representational Gestures Help Speaking. In David McNeill, ed., Language and Gesture, 162-185. Cambridge, MA: MIT Press.

Klahr, David, and M. Robinson. 1981. Formal Assessment of Problem Solving and Planning Processes in Preschool Children. Cognitive Psychology 13:113-148.

Lenneberg, Eric H. 1964. Capacity for Language Acquisition. In J. A. Fodor and J. J. Katz, eds., The Structure of Language: Readings in the Philosophy of Language. NJ: Prentice-Hall.

Mayberry, Rachel I. 1992. The Cognitive Development of Deaf Children: Recent Insights. In S. Segalowitz and I. Rapin, eds., Child Neuropsychology, 51-68. 
Handbook of Neuropsychology, Vol. 7. Ed. F. Boller and J. Graffman. Amsterdam: Elsevier.

McNeill, David. 1992. Hand and Mind: What Gestures Reveal about Thought. Chicago: The University of Chicago Press.

Meltzoff, Andrew N., and M. K. Moore. 1977. Imitation of Facial and Manual Gestures by Human Neonates. Science 198:75-78.

Moores, Donald F. 1974. Nonvocal Systems of Verbal Behavior. In R. L. Schiefelbusch and L. L. Lloyd, eds., Language Perspectives: Acquisition, Retardation, and Intervention. Baltimore: University Park Press.

Morford, Jill P., and Susan Goldin-Meadow. 1997. From Here to There and Now to Then: The Development of Displaced Reference in Homesign and English. Child Development 68:420-435.

Newport, Elissa L., and Richard Meier. 1985. The Acquisition of American Sign Language. In Dan I. Slobin, ed., The Cross-Linguistic Study of Language Acquisition, Vol. 1. Hillsdale, NJ: Erlbaum.

Ozcaliskan, Seyda, and Susan Goldin-Meadow. 2005. Gesture Is at the Cutting Edge of Early Language Development. Cognition 96:B01-113.

Ozyurek, Asli, and Sotaro Kita. 1999. Expressing Manner and Path in English and Turkish: Differences in Speech, Gesture, and Conceptualization. Proceedings of the Cognitive Science Society 21:507-512.

Perry, Michelle, and Anastasia D. Elder. 1997. Knowledge in Transition: Adults' Developing Understanding of a Principle of Physical Causality. Cognitive Development 12:131-157.

Perry, M., D. B. Berch, and J. L. Singleton. 1995. Constructing Shared Understanding: The Role of Nonverbal Input in Learning Contexts. Journal of Contemporary Legal Issues, Spring, 213-236.

Perry, Michelle, Ruth Breckinridge Church, and Susan Goldin-Meadow. 1988. Transitional Knowledge in the Acquisition of Concepts. Cognitive Development 3:359-400.

Phillips, Sarah, Susan Goldin-Meadow, and Peggy Miller. 2001. Enacting Stories, Seeing Worlds: Similarities and Differences in the Cross-Cultural Narrative Development of Linguistically Isolated Deaf Children. Human Development 44:311-336.

Pine, Karen, Nicola Lufkin, and Daniel Messer. 2004. More Gestures than Answers: Children Learning about Balance. Developmental Psychology 40:1059-1067.

Shatz, Marilyn. 1982. On Mechanisms of Language Acquisition: Can Features of the Communicative Environment Account for Development? In Eric Wanner and Lila R. Gleitman, eds., Language Acquisition: The state of the Art, 102-127. New York: Cambridge University Press.

Singer, Melissa A., and Susan Goldin-Meadow. 2005. Children Learn When Their Teachers' Gestures and Speech Differ. Psychological Science 16:85-89.

Singleton, Jenny, Jill Morford, and Susan Goldin-Meadow. 1993. Once Is Not Enough: Standards of Well-Formedness in Manual Communication Created 


\section{When Gesture Is and Is Not Language}

over Three Different Timespans. Language 69:683-715.

Slobin, Dan I. 1996. From "Thought and Language" to "Thinking for Speaking". In J. J. Gumperz and S. C. Levinson, eds., Rethinking Linguistic Relativity, 97-114. Cambridge: Cambridge University Press.

Talmy, Leonard. 1985. Lexicalization Patterns: Semantic Structure in Lexical Forms. In T. Shopen, ed., Language Typology and Syntactic Description, Vol. III: Grammatical Categories and the Lexicon, 57-149. Cambridge: Cambridge University Press.

Tervoort, Bernard T. 1961. Esoteric Symbolism in the Communication Behavior of Young Deaf Children. American Annals of the Deaf 106:436-480.

Thurnham, Angela, and Karen Pine. 2006. The Effects of Single and Dual Representations on Children's Gesture Production. Cognitive Development 21:46-59.

Valenzeno, L., Martha Alibali, and Roberta Klatzky. 2003. Teachers' Gestures Facilitate Students' Learning: A Lesson in Symmetry. Contemporary Educational Psychology 28:187-204.

Wagner, Susan, Howard Nusbaum, and Susan Goldin-Meadow. 2004. Probing the Mental Representation of Gesture: Is Handwaving Spatial? Journal of Memory and Language 50:395-407.

Susan Goldin-Meadow

University of Chicago

Departments of Psychology and Comparative Human Development

5730 South Woodlawn Avenue

Chicago, IL 60637

sgm@uchicago.edu 